\title{
Synthesis and Evaluation of Water Insoluble but Swellable Bioadhesive Polymer for Ocular Drug Delivery
}

\author{
Chaudhari Praveen*, Desai Ujwala
}

Department of Pharmaceutics, PES' Modern college of Pharmacy, Sector no. 21, Yamunanagar, Nigdi, Pune 411044, Maharashtra, INDIA.

\begin{abstract}
Introduction: Our main purpose of present study was to find out the effect of different crosslinking agents along with its concentration during polymer synthesis and to find the most suitable polymer for ocular drug delivery with optimum bioadhesive strength and less irritation potential. It was expected that the synthesized polymer will remain adhered to the conjunctival mucin layer thus preventing loss of drug by precorneal factors. Materials and methods: Acrylic acid procured from Loba chemicals was polymerized with Divinyl glycol from Merck specialities Private limited, Divinylbenzene and 2, 5-dimethyl-1, 5-hexadiene from Alfa Aesar to form water insoluble swellable polymer. Different parameters like density, polymer hydration, Differential Scanning Calorimetry, Infra-Red spectroscopy, $\mathrm{X}$ ray diffraction and mucoadhesive strength were determined. Polymer hydration was studied with respect to time, $\mathrm{pH}$ and ionic strength. HET-CAM test and Draize skin irritation test was performed to evaluate the degree of irritation caused by these polymers. Results and Discussion: It was found that as more hydrophobic groups were introduced in the polymer structure, hydration potential was reduced. The effect of concentration of crosslinking agent on bioadhesive strength was significant. With increase in density of crosslinking agent, the bioadhesive strength decreased. Polymers were found to be non-irritant to slight irritant in nature.
\end{abstract}

Key words: Bioadhesion, Ocular, Water Insoluble polymer, Acrylic acid, Hydration.

\section{INTRODUCTION}

The most probable reasons responsible for low ocular bioavailability of drugs include the precorneal loss factors which include tear dynamics (blinking reflex and tear turnover), ${ }^{1}$ non-productive absorption, transient residence time in the cul-de-sac, relative impermeability through corneal epithelial membrane, rapid precorneal elimination, drainage by gravity, frequent instillation, enzymatic metabolism, nasolacrimal drainage and the absence of controlled release.-9 Only $\leq 1 \%$ of administered drug dose is absorbed ocularly because of the factors mentioned above. ${ }^{10,11}$ Thus increasing the dosing frequency of drugs becomes the requirement in ocular drug delivery to achieve therapeutic concentration of drug which may lead to surge in local and systemic side effects like gastrointestinal disorders. ${ }^{12}$ The side effects can be overcome by opting for systemic route, but the blood brain barrier and blood aqueous barrier further leads to high loading dose. The difficulties involved in conventional ocular therapy can be overcome by various approaches like liposomes, niosomes, nanoparticles, microparticles, gel based drug delivery system, ocuserts and bioadhesive systems., $3,13,14$

Use of bioadhesive polymer proves to be the solution where polymeric substances remains attached to precorneal surface through non covalent bonds. ${ }^{15}$ Literature survey ${ }^{16,17}$ showcased two points after thorough study of polymer's binding affinity to
Submission Date: 20-10-2018; Revision Date: 27-11-2018; Accepted Date: 12-12-2018

DOI: 10.5530/ijper.53.2.30 Correspondence: Dr. Chaudhari Praveen, Department of Pharmaceutics, PES' Modern college of Pharmacy, Sector no. 21, Yamunanagar, Nigdi, Pune 411044, Maharashtra, INDIA.

Phone: 020-27661314

E-mail: pdchaudhari21@ rediffmail.com

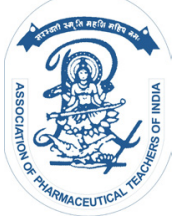

www.ijper.org 
mucin epithelial surface for bioadhesion process. First point was the polyanionic and water insoluble polymer would offer more advantages over neutral drug delivery system/ polycationic polymer and water soluble polymer respectively. Second point was that presence of carboxylic acid would be preferred over other functional groups as it relates with bioadhesion. ${ }^{16}$ Acrylic acid polymers are example of water insoluble swellable polymer which has wide water holding capacity. ${ }^{17}$ Following properties should be exhibited by the bioadhesive polymer: a) non toxic b) non absorbable at target site c) should adhere to the conjunctival mucin/epithelial surface by non covalent bond d) quick adhesion e) easy inclusion of drug without any interference to its release $\mathrm{f}$ ) cost effective. The objectives behind the present study was to synthesize series of polymers by using different crosslinking agents, to investigate its physicochemical properties and to find out best suitable polymer for ocular drug delivery with optimum bioadhesion and less irritation potential to animals. Monomer acrylic acid was crosslinked with three different cross linking agents namely divinyl glycol, divinyl benzene and 2,5-dimethyl-1,5-hexadiene to produce series of polymers and evaluated for its suitability for ocular drug delivery.

\section{MATERIALS AND METHODS}

\section{Materials}

Acrylic acid and benzoyl peroxide were obtained from Loba Chemicals. Magnesium sulfate heptahydrate and Divinyl glycol were procured from Merck Specialities Private Limited. Divinylbenzene and 2,5-dimethyl1,5-hexadiene were purchased from Alfa Aesar. All of the above chemicals were of analytical grade.

\section{Method}

In $100 \mathrm{gm}$ acrylic acid, one gram of benzoyl peroxide (initiator) was dissolved. The cross-linking agent (divinyl benzene/ divinyl glycol/ 2,5-dimethyl-1,5-hexadiene) was added in three different concentrations $(0.3 / 0.6 / 1 \mathrm{~g})$ with stirring in to a solution containing $800 \mathrm{~g}$ of magnesium sulfate $\left(\mathrm{MgS}_{04} \cdot 7 \mathrm{H}_{20}\right)$ in $100 \mathrm{~mL}$ of distilled water and refluxed at temperature of $95^{\circ} \mathrm{C}$. Polymerization was achieved within 30 min of reflux. After polymerization, the mixture was maintained at the same temperature with stirring for $2 \mathrm{~h}$ of curing time. At the end of the reaction, the mixture was diluted with $150 \mathrm{~mL}$ of hot water and then repeatedly washed with equal portions of water. The washed cross-linked polymer was dried in a hot air oven at $90^{\circ} \mathrm{C}$ for a specified time before being ground to the required size (30-40 mesh). ${ }^{18}$

\section{Physicochemical Properties of Polymers Yield and Density}

The density of each polymer was determined in a $2 \mathrm{ml}$ specific gravity bottle at $25^{\circ} \mathrm{C}$. Benzene of known density $(0.874 \mathrm{~g} / \mathrm{ml})$ was used as the medium because no swelling of the polymer in benzene was observed. ${ }^{17}$

\section{Polymer hydration}

Each polymer was weighed $0.2 \mathrm{~g}$ and allowed to hydrate in $10 \mathrm{~mL}$ of distilled water at $25^{\circ} \mathrm{C}$ in a $25-\mathrm{mL}$ graduated cylinder. The volume of the hydrated polymer was measured at 5-min intervals until the rise in hydrated volume was constant. ${ }^{17}$

\section{Effect of $\mathrm{pH}$ on swelling of polymer}

In $100 \mathrm{ml}$ test solution, $50 \mathrm{mg}$ polymer was introduced and allowed to hydrate at $37^{\circ} \mathrm{C}$ for $24 \mathrm{~h}$ with occasional stirring to remove trapped air bubbles. The $\mathrm{pH}$ of the solution was constantly checked and adjusted with saturated sodium hydroxide solution, if required, to maintain $\mathrm{pH}$. After $24 \mathrm{~h}$, the fully hydrated polymer was transferred to a $10-\mathrm{mL}$ graduated cylinder and allowed to settle. After several h, the increase in hydration volume was measured. The test solutions were HCL of $\mathrm{pH} 1.2$ and 2, $0.1 \mathrm{M}$ monobasic potassium phosphate of $\mathrm{pH} 3,4,5,6,7$. $^{18}$

\section{Effect of time on swelling ratio ${ }^{18}$}

Polymer $(0.1 \mathrm{~g})$ was placed in $10 \mathrm{ml}$ distilled water. At different time intervals like 5, 10, 15, 20, 25,30,35,40, $50,60,90,120,150,180,210,240 \mathrm{~min}$, weight of swollen polymer was noted. The swelling ratio was calculated as

Swelling ratio $=$ weight of swollen polymer- initial weight of polymer/ initial weight of polymer

\section{Effect of ions on swelling ratio}

Polymer $(0.1 \mathrm{~g})$ was dissolved in $0.1 \mathrm{M}$ different solutions for $2 \mathrm{hrs}$. The solutions were prepared in a manner where polymer was exposed to different monovalent and divalent ionic solutions. The hydrated polymer was weighed after 2 hrs and the swelling ratio was determined by formula as mentioned in above procedure. ${ }^{17,18}$

\section{FTIR spectrometry}

Infrared spectrums of polymers were determined on Fourier Transform Infrared Spectrophotometer (FTIR 4100, Jasco) using $\mathrm{KBr}$ dispersion method. The base line correction was done using dried potassium bromide. The samples to be analysed and $\mathrm{KBr}$ were previously dried in oven for $30 \mathrm{~min}$ and mixed thoroughly with potassium bromide in 1:300 (sample: $\mathrm{KBr}$ ) ratio in a 
glass mortar. These samples were then placed in a sample holder and scans were obtained at a resolution of $2 \mathrm{~cm}^{-1}$ from 4000 to $400 \mathrm{~cm}^{-1}$.

\section{Ex vivo Mucoadhesive strength determination}

The mucoadhesive force which is defined as detachment stress of the polymer was determined by using a modification of weighing balance. Fresh goat lower eyelids of both eyes were bought from slaughter house and placed in an aerated saline solution until used. One of the eyelids was secured over a weighted glass vial using a rubber band so that the conjunctiva faced outwards. The vial was then placed in a jacketed beaker thermostated at $37^{\circ} \mathrm{C}$ containing $500 \mathrm{ml} \mathrm{pH} 7.4$ isotonic Sorensen buffer and positioned under the scale. Another eyelid was placed on rubber stopper of another vial which was hanged on the balance. One vial was connected to the balance and the other fixed with polymer gel and the height was adjusted so that the polymer is placed between mucosal sides of both vials. Water from the burette was allowed to fall drop by drop till the detachment of vials. Mucoadhesive force was determined from minimal weights of water that detached the vial. ${ }^{17,19}$

Mucoadhesive strength $($ dynes $/ \mathrm{cm} 2)=\mathrm{mg} / \mathrm{A}$

Where, $\mathrm{m}=$ Weight required for detachment in $\mathrm{g}$

$\mathrm{g}=$ acceleration due to gravity $\left(980 \mathrm{~cm} / \mathrm{s}^{2}\right)$

$A=$ area of mucosa exposed $\left(\mathrm{cm}^{2}\right)$

\section{Differential Scanning Calorimetry}

DSC measurements were performed on a differential scanning calorimeter (DSC Mettler STAR SW 9.20, Switzerland). Nitrogen gas was purged at a flow rate of $50 \mathrm{ml} / \mathrm{min}$ in order to maintain inert atmosphere. In a sealed aluminium pan, all accurately weighed samples were placed and the heating of samples was carried out at the rate of $10^{\circ} \mathrm{C} / \mathrm{min}$ under nitrogen gas flow $(20 \mathrm{ml} / \mathrm{min})$ for $40-340^{\circ} \mathrm{C}$. An empty aluminum pan was used as reference.

\section{Ray Diffraction analysis}

X-ray diffraction patterns of the polymer samples were recorded using Philips PW3710 Analytical XRD B. V. $\mathrm{X}$-ray diffractometer using $\mathrm{Cu} \mathrm{K} 2 \alpha$ rays with a voltage of $40 \mathrm{kV}$ and a current of $25 \mathrm{~mA}$. Samples were scanned for $2 \theta$ from 5 to 500 . Diffraction patterns of polymers were obtained using an X-ray diffractometer (mod. D8 Discover, Bruker, USA).

\section{Conjunctival (HET-CAM) test ${ }^{20}$}

Fertilized hen's eggs were freshly bought from poultry farm and were kept in incubation chamber at tempera- ture $37.5 \pm 0.5{ }^{\circ} \mathrm{C}$ and $66 \pm 5 \%$ Relative humidity $(\mathrm{RH})$ for a period of three days. On third day, eggshells were broken and inner content was exposed on petri plate. The main criterion for this test was only viable embryo with intact CAM and yolk sacs were used and further incubated. The conjunctival irritation potential of the polymers was investigated. On tenth day, $0.1 \mathrm{~g}$ (solid) of each polymer was placed on the membrane. The test was carried out in triplicates. Following were the chemicals used as standards in order to compare the degree of irritation. Sodium hydroxide $(0.5 \mathrm{M})$ was used as positive control strong irritant, acetone as moderate irritant, propylene glycol as slight irritant and normal saline solution as negative control. ${ }^{21}$ The blood vessels and capillaries were inspected for irritation effects. The irritation effects considered in order to classify the polymers on degree of irritation after instillation for 5 min were hyperaemia, haemorrhage and clotting. ${ }^{22}$ Based on how much time is required for each effect to occur by each polymer, a time-dependent numerical score was assigned (Table 1). A single numerical value was calculated by addition of numerical values obtained for each irritant response and which ultimately determined degree of irritation potential (Table 2). The clas-

\begin{tabular}{|c|c|c|c|c|}
\hline $\begin{array}{l}\text { Monomer } \\
(100 \mathrm{gm})\end{array}$ & $\begin{array}{c}\text { Cross-Linking } \\
\text { agent }\end{array}$ & $\begin{array}{l}\text { Quantity } \\
\text { (gm) }\end{array}$ & $\begin{array}{l}\text { Polymer } \\
\text { code }\end{array}$ & Initiator \\
\hline \multirow[t]{3}{*}{ Acrylic acid } & Divinyl glycol & \multirow[t]{3}{*}{0.3} & DG1 & \multirow{9}{*}{$\begin{array}{l}\text { Benzoyl } \\
\text { peroxide }\end{array}$} \\
\hline & Divinylbenzene & & DB1 & \\
\hline & $\begin{array}{l}\text { 2,5,-Dirnethyl- } \\
\text { I,5hexadiene }\end{array}$ & & HD1 & \\
\hline \multirow[t]{3}{*}{ Acrylic acid } & Divinyl glycol & \multirow[t]{3}{*}{0.6} & DG2 & \\
\hline & Divinylbenzene & & DB2 & \\
\hline & $\begin{array}{l}\text { 2,5,-Dirnethyl- } \\
\text { I,5hexadiene }\end{array}$ & & HD2 & \\
\hline \multirow[t]{3}{*}{ Acrylic acid } & Divinyl glycol & \multirow[t]{3}{*}{1} & DG3 & \\
\hline & Divinylbenzene & & DB3 & \\
\hline & $\begin{array}{l}\text { 2,5,-Dirnethyl- } \\
\text { I,5hexadiene }\end{array}$ & & HD3 & \\
\hline
\end{tabular}

\begin{tabular}{|c|c|c|c|c|c|}
\hline \multirow[b]{2}{*}{ Effect/time (min) } & \multicolumn{3}{|c|}{ Score } & \multirow{2}{*}{$\begin{array}{c}\begin{array}{c}\text { Cumulative } \\
\text { score }\end{array} \\
0-0.9 \\
\end{array}$} & \multirow{2}{*}{$\begin{array}{c}\begin{array}{c}\text { Irritation } \\
\text { assessment }\end{array} \\
\text { None }\end{array}$} \\
\hline & 0.5 & 2 & 5 & & \\
\hline Hyperemia & 5 & 3 & 1 & $1.0-4.9$ & Slight \\
\hline Haemorrhage & 7 & 5 & 3 & $5.0-8.9$ & Moderate \\
\hline $\begin{array}{l}\text { Clotting/ } \\
\text { coagulation }\end{array}$ & 9 & 7 & 5 & $9.0-21.0$ & Severe \\
\hline
\end{tabular}


sification system used to determine irritation potential was similar to that used in Draize test. ${ }^{23}$

\section{Primary skin irritation test}

Two healthy albino rabbits were used for the experiment. Animal husbandry was conducted in accordance with the "Guide for the Care and use of Laboratory Animals," NIH publication No.85-23.

Methods: The backs of the animals were cleaned free of fur with a razor atleast 4 hrs before application of the sample. One $\mathrm{ml}$ sample of the least irritant polymer obtained from ex vivo test was then applied to the particular site to an area of skin approximately 1 " $\times 1$ " $(2.54 \times 2.54 \mathrm{~cm})$ square. The sample applied site was covered with a nonreactive tape. Animals were returned to their cages. After a $24 \mathrm{hrs}$ exposure, the tape was removed and the test sites were wiped with tap water to remove the test sample. At 24 and 72 hrs after test sample application, the test sites were examined for dermal reactions in accordance with the FHSArecommended Draize scoring criteria (Appendix 1). The Primary Irritation Index (P.I.I.) of the test sample was calculated following test completion..$^{24,25}$

\section{In vivo Draize eye irritation test}

The Draize test was performed on white albino rabbits. In this test $100 \mu \mathrm{g}$ test sample was placed into the lower cul-de-sac of rabbit's right eye (1.5-2 kg, 13 week of age). Left eye was treated as a control. Rabbits' eyes were observed periodically for redness, swelling and watering of the eye at $1 \mathrm{~h}, 4 \mathrm{~h}$ and every $24 \mathrm{~h}$ for 7 days. Three rabbits were used for test substance. These parameters were calculated from weighted scores for each part of the rabbit eye such as (cornea, iris and conjunctiva) and also from the sum of these scores. The maximal average Draize total scores (MAS) are classified into non-irritants $(0<$ MAS $<0.5)$, slight irritants $(0.5<$ MAS $<15)$, mild irritants $(15<\mathrm{MAS}<25)$, moderate irritants $(25<\mathrm{MAS}<50)$ and severe irritants $(50<\mathrm{MAS}) .{ }^{26}$ Approval of the institutional animal ethics committee (Approval No. MCP/ IAEC/01/2016) was obtained prior to the commencing of the study from Modern college of Pharmacy, Nigdi, Pune.

\section{RESULTS AND DISCUSSION}

\section{Yield and density}

Polymerization occurred within a period of $30 \mathrm{~min}$. While synthesis, extensive swelling of produced polymer was overcome by use of magnesium sulphate heptahydrate which served as suspending agent. Significant yields were obtained in case of all the polymers. The results indicated in Table 3 shows that the effect of concentration of crosslinking agent on density was insignificant. In addition to this, use of different crosslinking agent also had very small fraction of influence on density parameter.

\section{Polymer hydration}

The effect of different crosslinking agent on the extent of hydration is shown in Figure 1. The rate and extent of hydration plays an important role in practical implications because swelling increases surface area. It was observed that hydration of polymer occured quickly in water and equilibrium was achieved within 30-40 min (Figure 1). The degree of hydration was not significantly affected by change in either crosslinking agent or its concentration. Smaller-sized particles hydrate more quickly than larger-sized particles because the penetration of water molecules through small particles is easy due to lesser thickness of small particles.

\section{Effect of $\mathrm{pH}$ on swelling of polymer}

Equilibrium swelling of polymer was measured at different $\mathrm{pH}$ values and corresponding profiles are shown in Figure 2. In acidic pH (upto 4), the increase in swelling was slight. As the $\mathrm{pH}$ started increasing above 4, significant degree of swelling was observed upto $\mathrm{pH} 7$. In the process of polymer hydration, the dependence of water movement into the polymer network in the presence of electrolytes is known to be a characteristic typical of Donnan membrane equilibrium. Since the pKa of polyacrylic acid is $4.75,{ }^{17} \mathrm{pH}$ dependent equilibrium swelling was expected. The polyacrylic acid consists of large number of carboxylic $(\mathrm{COOH})$ groups along the polymer backbone which makes it $\mathrm{pH}$ sensitive, hydrophilic and capable of forming hydrogen bonds. ${ }^{27}$

\begin{tabular}{|c|c|c|c|}
\multicolumn{4}{|c|}{ Table 3: Yield and density of crosslinked swelling } \\
polymers. \\
\hline Sr. No. & Polymer & Yield (\%) & Density \\
\hline 1. & DB1 & $72 \pm 0.208$ & $1.458 \pm 0.237$ \\
\hline 2. & DB2 & $69 \pm 0.251$ & $1.462 \pm 0.319$ \\
\hline 3. & DB3 & $78 \pm 0.372$ & $1.483 \pm 0.456$ \\
\hline 1. & DG1 & $87 \pm 0.637$ & $1.529 \pm 0.163$ \\
\hline 2. & DG2 & $81 \pm 0.432$ & $1.572 \pm 0.089$ \\
\hline 3. & DG3 & $89 \pm 0.312$ & $1.595 \pm 0.504$ \\
\hline 1. & HD1 & $94 \pm 0.583$ & $1.622 \pm 0.275$ \\
\hline 2. & HD2 & $96 \pm 0.291$ & $1.636 \pm 0.328$ \\
\hline 3. & HD3 & $92 \pm 0.726$ & $1.641 \pm 0.461$ \\
\hline
\end{tabular}




\section{Effect of time on swelling ratio}

Figure 3 shows that all of the polymers tested hydrate quickly in water, reaching equilibrium in 20-40 min. Once the equilibrium swelling was attained, the increase in swelling ratio was more or less constant. Smaller-sized particles hydrated faster than larger-sized particles. The polymer molecules in dry state are highly coiled and tightly packed structures. When placed in water, they behave as anionic electrolytes. They dissociate and partially uncoil due to repulsion of negative charges generated along the polymer chains. The subsequent swelling is caused by difference in osmotic pressure inside the vicinity of polymer chains (cluster) and bulk medium. $^{28}$

\section{Effect of ions on swelling ratio}

Literature review ${ }^{29}$ indicated that the important influential factors were the ion strength of solution and the valency of cation. They considered that the electrostatic may be the main reason that the gel absorbs the water. The swelling characteristics of polymer at same ionic strength in acid, base and salt was measured. The study showed that the effect of different ions did not cause any significant change in the swelling of drug (Figure 4). Monovalent and divalent ions also did not affect the swelling characteristics of polymer. The increase in swelling for solutions like $\mathrm{NaOH}, \mathrm{NaHCO}_{3}, \mathrm{~K}_{2} \mathrm{HP}$ O4 was attributed to change in swelling of reaction mixture solution (Basic solution) and not due to presence of ions. This was confirmed by use of other salts containing same ions but did not show swelling. Figure 4 proves that electrostatic is not the main reason that the hydrogel absorbs water at room temperature. The effect of temperature on swelling ratio showed similar results where there was no significant effect observed with respect to change in temperature (from $25^{\circ} \mathrm{C}$ to $60^{\circ} \mathrm{C}$ ). Thus ultimately it proved that the bioadhesive property was not affected by presence of ions or with change in temperature.

\section{FTIR}

(A) Figure 5(A) exhibits following wavenumbers 720.282, 1467.56, 1736.58, 2849.31, $3402.78 \mathrm{~cm}^{-1}$ denotes Rocking band $-\mathrm{CH}_{2}$ - bending (long chain band), $-\mathrm{CH}_{2}$ - bending, $\mathrm{C}=\mathrm{O}$ carboxylic acid, Tertiary $\mathrm{C}-\mathrm{H}$ symmetric stretching, $\mathrm{sp}=\mathrm{C}-\mathrm{H}$ stretching band respectively. The tertiary $\mathrm{C}-\mathrm{H}$ (methine hydrogen) gives weak $\mathrm{C}-\mathrm{H}$ absorption near $2890 \mathrm{~cm}-1$. Methylene hydrogen $\left(-\mathrm{CH}_{2}-\right)$ gives rise to two $\mathrm{C}-\mathrm{H}$ stretching bands representing the symmetric (sym) and asymmetric (asym) stretching modes of group. In effect, $2890 \mathrm{~cm}-1$ methine absorption is split into 2 bands $2926 \mathrm{~cm}-1$ (asym) and $2853 \mathrm{~cm}-1$ (sym). The free carboxylic group was retained which is found to be responsible for bioadhesion. Four acrylic acid molecules are assumed to be bound together by one molecule of crosslinking agent viz divinyl benzene (Figure 5(D)).

(B) Figure 5 (B) exhibits following wavenumbers 722.2, 1698, 2358.5, 2854, 3296, $3648.7 \mathrm{~cm}^{-1}$ denotes Bending motion associated with four or more $\mathrm{CH}_{2}$ groups in an open chain (long chain band), $\mathrm{C}=\mathrm{O}$ carboxylic acid stretching, $\mathrm{O}-\mathrm{H}$ carboxylic acid stretching, $-\mathrm{CH}_{2}-$ stretching asymmetric, $\mathrm{C}-\mathrm{H}$ alkane stretch, Free $-\mathrm{OH}$ group stretching respectively. The four acrylic acid groups are assumed to be bonded together by crosslinking agent viz divinyl glycol (Figure 5(D)).

(C) Figure 5 (C) exhibits following wave numbers 906.4, 1105, 1294, 1507.1, 1714.4, 2452, 2924.5, 3258.1 denotes $\mathrm{H}$-bonded $(\mathrm{O}-\mathrm{H})$ out of plane bending, $\mathrm{C}-\mathrm{O}$ stretch $\left(2^{\circ}\right.$ alcohol saturated), $\mathrm{C}-\mathrm{O}$ stretching band, $\mathrm{C}=\mathrm{C}$ stretching, $\mathrm{C}=\mathrm{O}$ carboxylic acid stretching, $\mathrm{O}-\mathrm{H}$ stretching vibration of carboxylic acid, C-H alkane stretching, $\mathrm{O}-\mathrm{H}$ (H-bonded stretching) respectively. The crosslinking agent viz 2,5-dimethyl-1,5-hexadiene assume to bond four molecules of acrylic acid (Figure 5(D)). ${ }^{30}$ Table 4 represents different substitution present in polymer structure due to different crosslinking agents.

The change in concentration of crosslinking agent did not show any significant change in IR spectra of these polymers. Hence only one spectra of each crosslinked polymer is discussed here in detail as a representative of that class. The purpose of this study was to evaluate the effects of crosslinking agents and which functional groups are responsible for these effects was suggested by IR spectroscopy

\section{Ex vivo Mucoadhesive strength}

The modified surface tensiometer method proved to be successful method to measure polymer adhesion to animal tissue unless the test conditions are maintained constant for all test samples. A primary mechanism of bioadhesion involves interpolation of the polymer with the mucin. The thickness of conjunctival mucin is considerably less and thus it becomes difficult for the polymer to have intimate contact. The adhesive force of the acrylic polymers was found to be sufficient for the conjunctival surface to maintain long contact time. The density of carboxyl group is important for mucoadhesion. The carboxyl groups present in polymer were found to be in protonated form and hence caused mucoadhesion to occur by hydrogen bonding. In addition, the density of the cross-linking agent significantly affects mucoadhesion. As the density of the cross- 


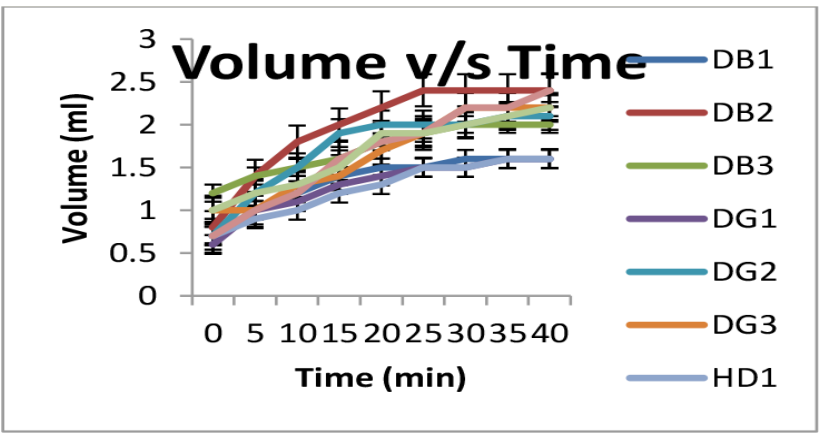

Figure 1: Graph of Hydration volume v/s time of cross linked swelling polymers.

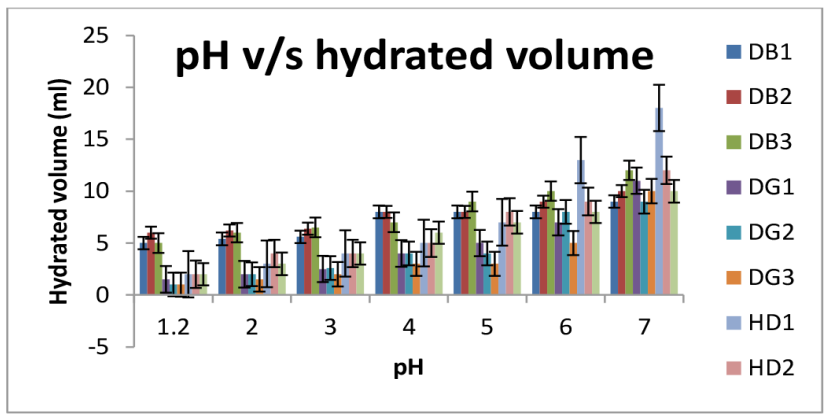

Figure 2: Graph of Hydrated volume v/s pH of cross linked swelling polymers.

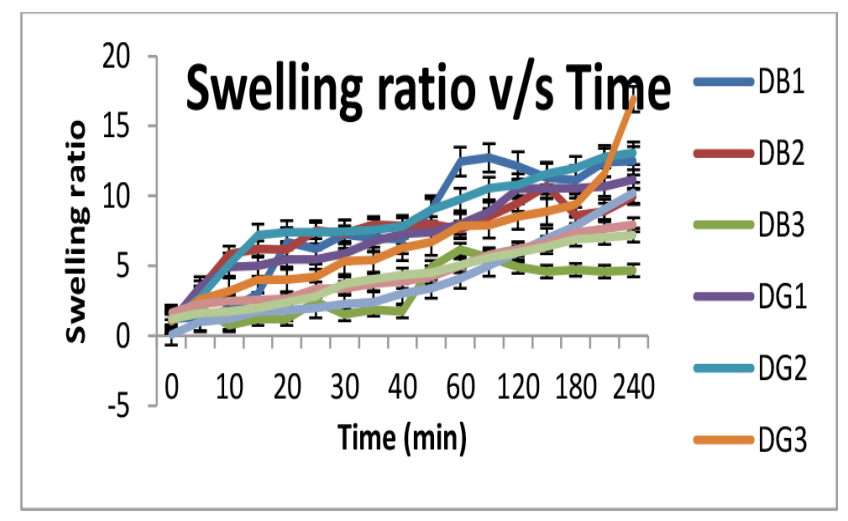

Figure 3: Plot of swelling ratio v/s time.

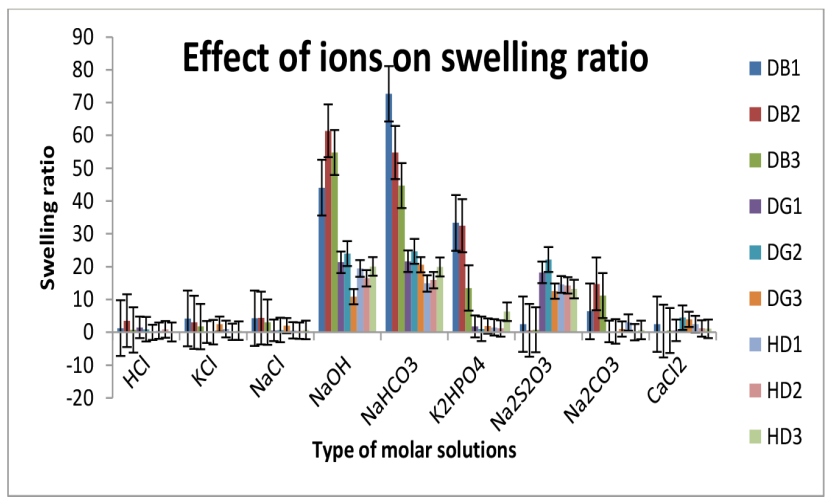

Figure 4: Plot of swelling ratio in different types of solution.

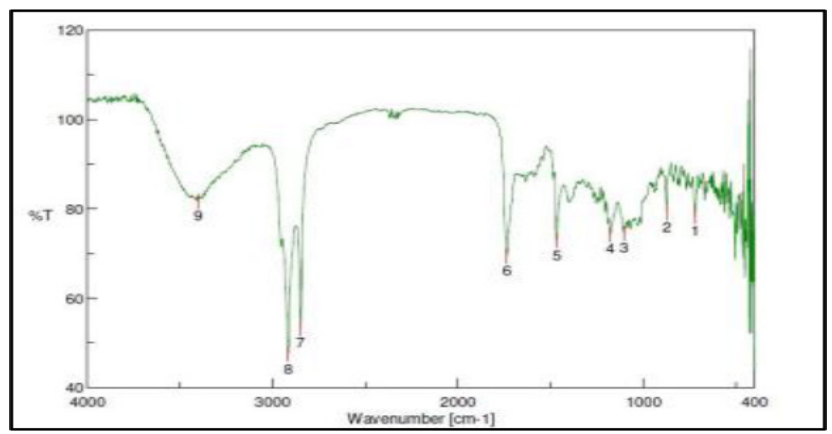

Figure 5(A): IR Spectra of DB1.

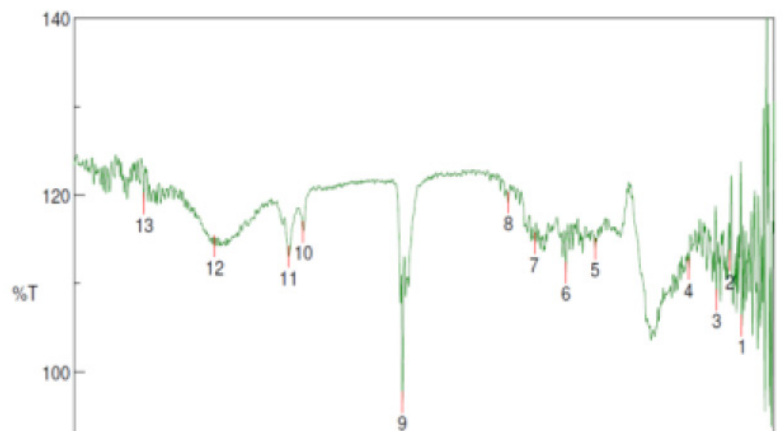

Figure 5(B): IR Spectra of DG1.

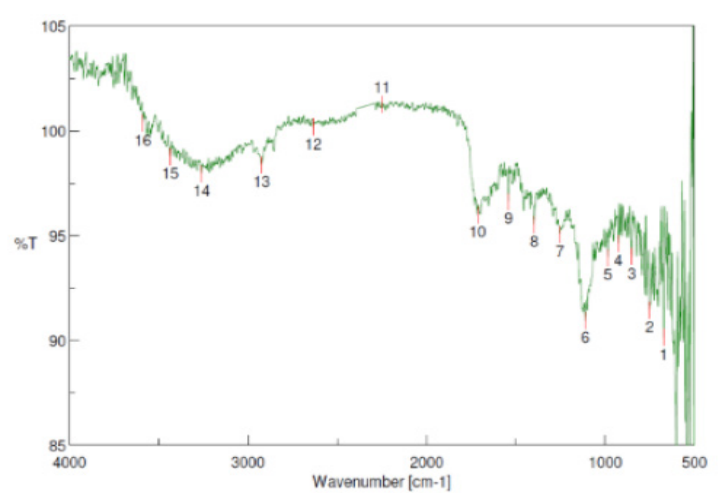

Figure 5(C): IR Spectra of HD1.

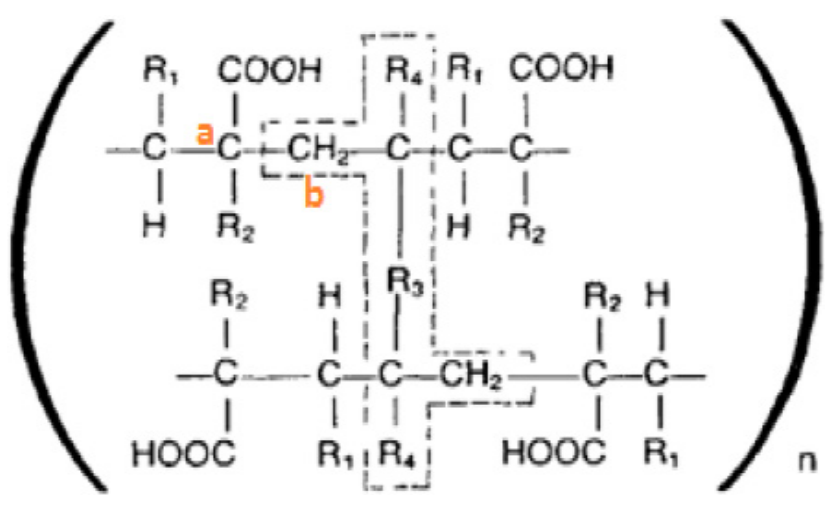

Figure 5(D): Probable structure of polymers. 
linking agent is lowered, the mucoadhesive strength increases (Table 5). It is concluded that for mucoadhesion to occur, polymers must have functional groups that are able to form hydrogen bonds above the critical concentration and the polymer chains should be flexible enough to form as many hydrogen bonds as possible. ${ }^{31}$

\section{Differential Scanning Calorimetry}

The thermograms (Figure 6A, 6B, 6C) exhibited two endothermic peaks. The first endothermic peak between $80-85^{\circ} \mathrm{C}$ is short and narrow peak assigned to the evaporation of water from hydrophilic groups in the polymers. The second one between $240-250^{\circ} \mathrm{C}$ corresponds to a thermal degradation through intermolecular anhydride formation and water elimination. ${ }^{32}$ There was no significant difference found in thermograms of individual polymer except that the temperature of both the endothermic peak in HD was increased. The most probable reason behind this increase could be presence of hydrophobic moiety in the form of crosslinking agent which requires more energy for breaking the bond in thermal degradation process.

\section{XRD analysis}

The X-ray diffraction pattern of polymer showed prominent diffraction peak at $19^{\circ}(2 \theta)$ and minor peak appears at $30^{\circ}(2 \theta)$ (Figure 7). These are the typical peaks of polyacrylic. The XRD spectra of all three polymers indicate that the samples are semi crystalline.

\begin{tabular}{|c|c|c|c|c|}
\hline \multicolumn{5}{|c|}{ Table 4: Mucoadhesive strength of polymer. } \\
\hline Polymer & R1 & R2 & R3 & R4 \\
\hline DB & H & H & $(p)-\mathrm{C}_{6} \mathrm{H}_{4}$ & H \\
\hline DG & H & H & $-\mathrm{CHOHCHOH}-$ & $\mathrm{H}$ \\
\hline HD & H & H & $-\mathrm{CH}_{2} \mathrm{CH}_{2}-$ & $\mathrm{CH}_{3}$ \\
\hline
\end{tabular}

\begin{tabular}{|c|c|c|c|}
\hline \multicolumn{4}{|c|}{ Table 5: Mucoadhesive strength of polymer. } \\
\hline $\begin{array}{c}\text { Sr. } \\
\text { No. }\end{array}$ & $\begin{array}{c}\text { Polymer } \\
\text { Code }\end{array}$ & $\begin{array}{c}\text { Weight required } \\
\text { for detachment } \\
\text { in g }\end{array}$ & $\begin{array}{c}\text { Mucoadhesive } \\
\text { strength (dynes/cm }{ }^{2} \text { ) }\end{array}$ \\
\hline 1. & DB1 & $2.2 \pm 0.057$ & $686.92 \pm 0.042$ \\
\hline 2. & DB2 & $2.43 \pm 0.063$ & $749.04 \pm 0.031$ \\
\hline 3. & DB3 & $2.57 \pm 0.039$ & $780.25 \pm 0.053$ \\
\hline 1. & DG1 & $1.49 \pm 0.041$ & $436.94 \pm 0.046$ \\
\hline 2. & DG2 & $1.62 \pm 0.026$ & $499.36 \pm 0.018$ \\
\hline 3. & DG3 & $2.0 \pm 0.037$ & $624.20 \pm 0.044$ \\
\hline 1. & HD1 & $2.63 \pm 0.046$ & $811.46 \pm 0.039$ \\
\hline 2. & HD2 & $3.87 \pm 0.028$ & $1185.98 \pm 0.027$ \\
\hline 3. & HD3 & $3.34 \pm 0.016$ & $1029.93 \pm 0.016$ \\
\hline 3. & HD3 & $3.3 \pm 0.021$ & $1029.93 \pm 0.011$ \\
\hline
\end{tabular}

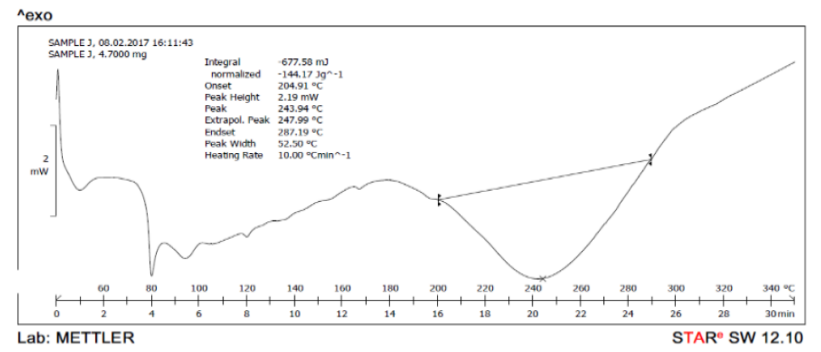

Figure 6(A): DSC spectra of DB1.

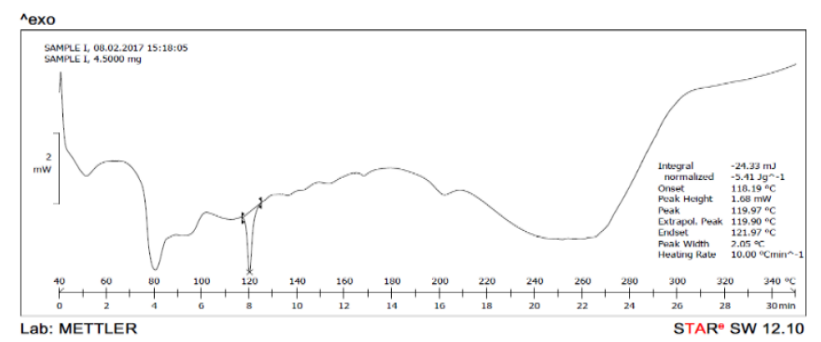

Figure 6(B): DSC spectra of DG1.

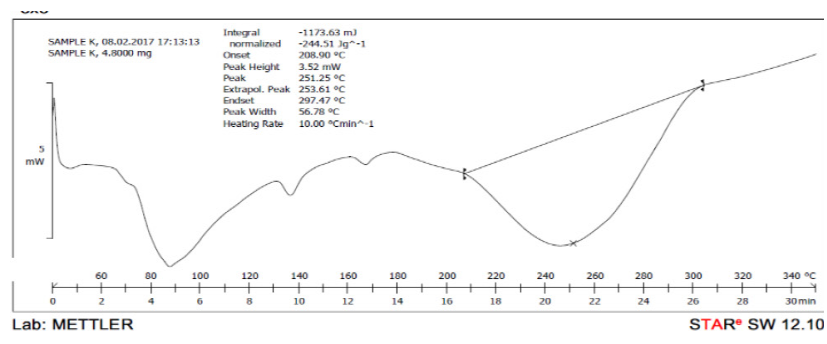

Figure 6(C): DSC spectra of HD1.

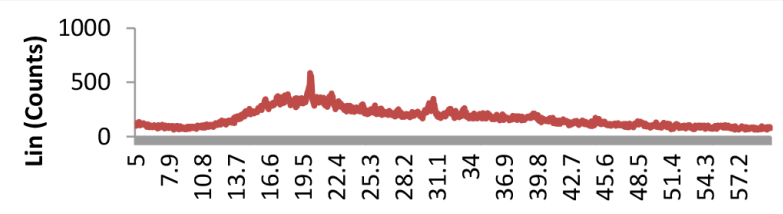

$2 \theta$

Figure 7(A): XRD spectra of DB1.

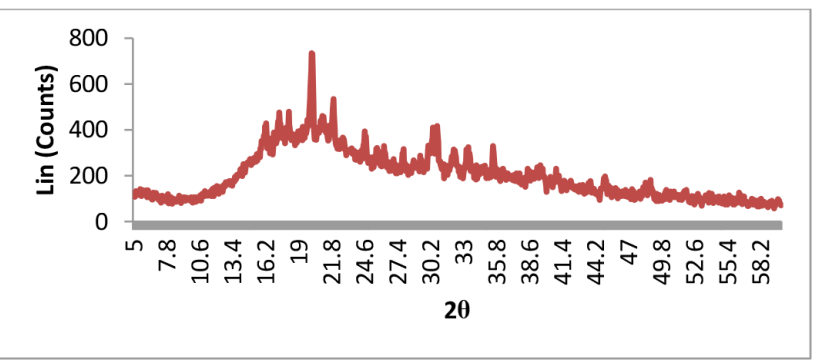

Figure 7(B): XRD spectra of DG1. 


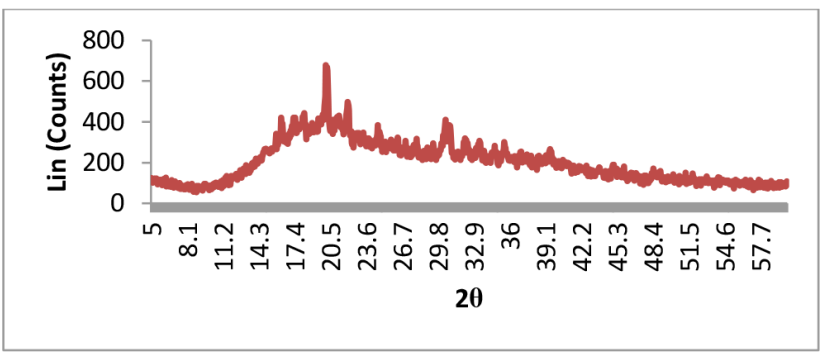

Figure 7(C): XRD spectra of HD1.

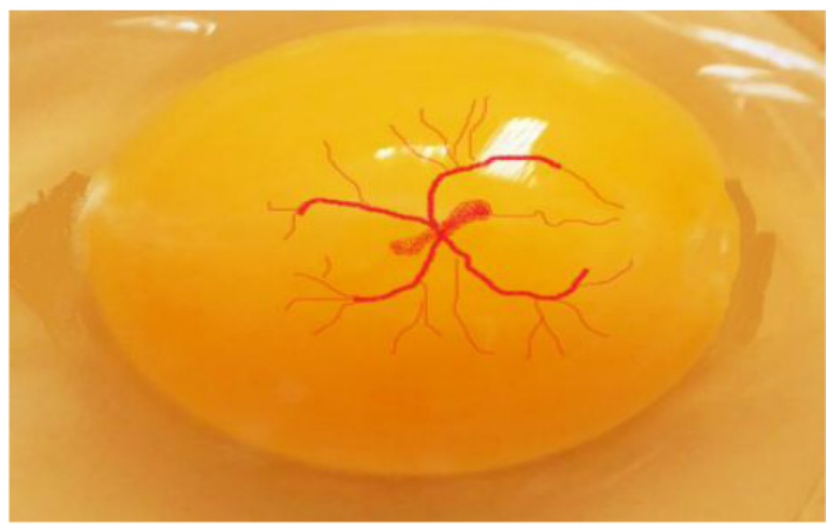

Figure 8: Developmental stages of growing embryo (A) embryo with intact yolk sac and CAM.

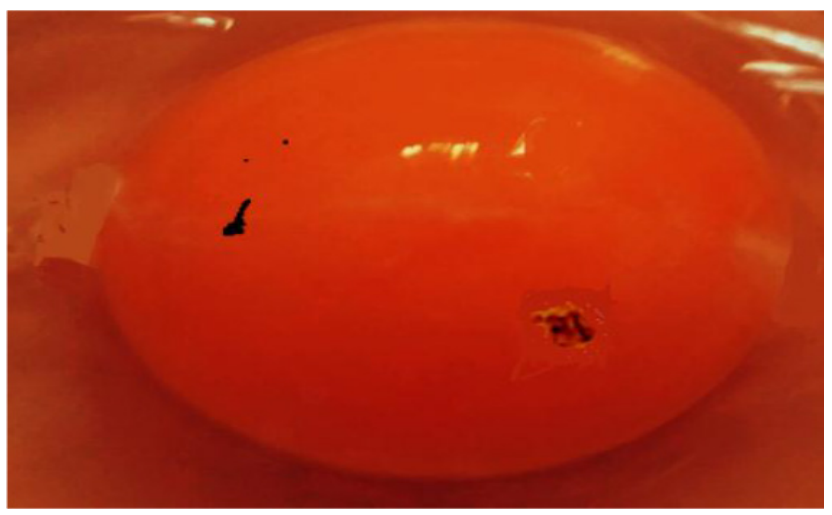

Figure 8(B): Dead embryo with intact yolk sac CAM.

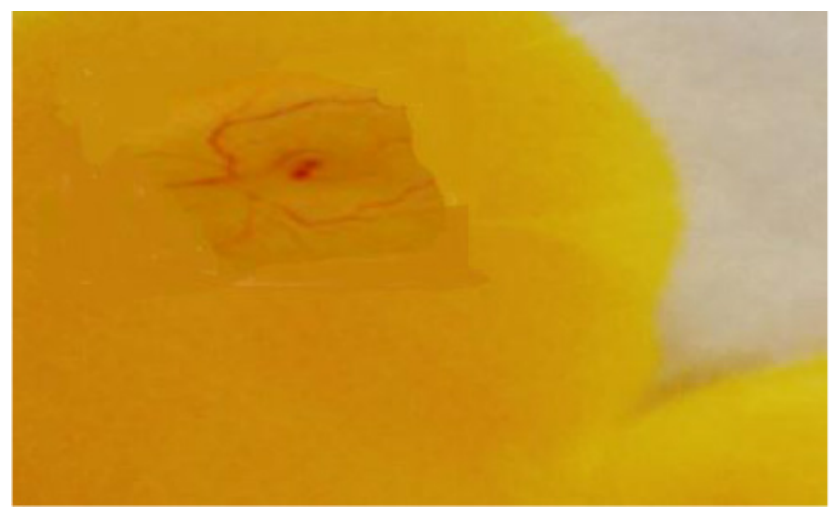

Figure 8(C): Embryo with broken yolk and intact CAM.
The inference can be validated by the intensity and number of peaks. There are few peaks which are sharp. Most of the spectra cover broad peak region indicating that the samples are semicrystalline. ${ }^{32}$

\section{HET CAM test}

Figure 8 outlines the development stages of the growing embryos. Embryos with intact yolk and viable CAM were only further incubated for 10 days. The test samples were applied on these ten days old CAMs. The temperature and relative humidity kept $37.5 \pm 0.5^{\circ} \mathrm{C}$ and $67 \pm 5 \%$ $\mathrm{RH}$ were found to be the optimum conditions for CAM growing. ${ }^{23,33}$ Initially the embryo were grown in the egg shell itself and later on to view the results, hole was drilled in the egg shell. The problems associated with it were limited visibility through the hole and chances of pieces of egg shell falling inside on surface of embryo while drilling the hole. Hence a modified method was reported in the literature, where the chick embryo was grown in a Petri dish from day 3 onwards to allow ready access to the entire CAM surface for better visibility and convenience. ${ }^{33}$ Thus the process of cracking and proper temperature and humidity conditions are necessary for the survival of the embryos and therefore the number of CAMs available for testing.

Figure 9 shows the cumulative HET-CAM scores for the controls and synthesized polymers. The average cumulative scores calculated for DG polymers were found to be $<0.9$. These results reveal that the DG polymers are practically non-irritant when applied to the surface of the CAM. Application of DB and HD polymers in a powder form developed minimal irritation potential in the form of hyperaemia after $3 \mathrm{~min}$. This indicates that DB and HD polymers are slight irritant when applied on the surface of the CAM.

\section{Primary skin irritation test}

The primary Irritation index of the test sample was calculated to be 0.00 ; No irritation was observed on the skin of the rabbits/ rats. Individual results of derma scoring appear in Table 6. The scores for erythema and

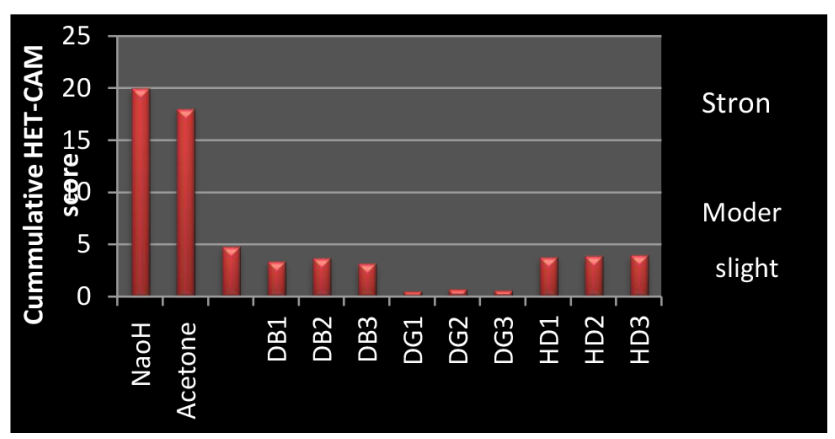

Figure 9: Cummulative HET-CAM score of polymers. 
Table 6: Reaction scores of animals to irritation potential.

\begin{tabular}{|c|c|c|c|}
\hline Animals & Reaction & 24 Hrs & 72 Hrs \\
\hline \multirow{2}{*}{ Rabbit 1 } & Erythema & 0 & 0 \\
\cline { 2 - 4 } & Edema & 0 & 0 \\
\hline \multirow{2}{*}{ Rabbit 2 } & Erythema & 0 & 0 \\
\cline { 2 - 4 } & Edema & 0 & 0 \\
\hline
\end{tabular}

Table 7: Irritation scores of animals to polymer.

\begin{tabular}{|c|c|c|c|c|}
\hline \multirow{2}{*}{ Days } & \multicolumn{5}{|c|}{ Observations } \\
\cline { 2 - 5 } & Cornea & Iris & Conjunctivae & Total \\
\hline 1 & 0 & 0 & 2 & 2 \\
\hline 2 & 0 & 0 & 2 & 2 \\
\hline 3 & 0 & 0 & 3 & 3 \\
\hline 4 & 0 & 0 & 2 & 2 \\
\hline 5 & 0 & 0 & 2 & 2 \\
\hline 6 & 0 & 0 & 0 & 0 \\
\hline
\end{tabular}

edema were summed for intact and abraded skin for rabbits at 24 and $72 \mathrm{hrs}$. The primary irritation index (P.I.I) was calculated. Based on the sum of the scored reactions divided by 32 (two scoring intervals multiplied by two test parameters multiplied by 8 animals). Primary Irritation Index: $0 / 32=0.00$. Under the conditions of this test, the test sample would not be considered a primary skin irritant since the primary Irritation Index was less than 5.00. Table 6 indicates the irritation scores of animals.

\section{In vivo Draize eye irritation test}

The results of the ophthalmic irritation studies were given in Table 7. The possibility of eye irritation due to polymer administration was evaluated in rabbits. The rabbits were observed for ocular lesions and no symptoms of ocular irritation such as redness, tearing, inflammation or swelling were observed after polymer administration. No ophthalmic damage or abnormal clinical signs to the cornea, iris or conjunctivae were visible. Thus, the developed ocular drug delivery systems are apparently free from any ocular irritation potential and can be safely administered to humans. The scores were calculated according to Draize scale.

\section{CONCLUSION}

Monomer acrylic acid was subjected to polymerization by using three different crosslinking agent namely divinylbenzene, divinyl glycol and 2,5-dimethyl-1,4-hexadiene. These crosslinking agents were used in different concentrations $(0.3,0.6,1 \mathrm{~g})$ with respect to $100 \mathrm{~g}$ mono- mer. The effect of different crosslinking agents on polymer swelling and hydration property was found to be insignificant. Similar results were obtained with respect to different concentrations of crosslinking agent. But the effect of different crosslinking agent on bioadhesion was significant. With decrease in density of crosslinking agent, the mucoadhesive strength was increased. The carboxylic groups present in polymer were responsible for bioadhesion process because the free protons would cause bioadhesion by hydrogen bonding. Thus more the number of free carboylic groups present in the polymer, more is the mucoadhesive strength. The XRD spectra indicated that all the polymers were found to be in semicrystalline in nature. The irritation potential measured by ex vivo HET- CAM test indicated that DG polymer were nonirritant and did not show any signs of inflammation and swelling. Thus DG polymer was further tested by in vivo draize skin and eye irritation test. The results coincided with the ex vivo test proving that the DG polymer was found to be non-irritant polymer. Thus the most appropriate and suitable polymer for ocular drug delivery with optimum swelling properties and good bioadhesive strength, non-irritant in nature is DG polymer viz poly acrylic acid linked by divinyglycol polymer. The DG polymer was further studied and used as bioadhesive polymer in ocular formulation (niosomal in situ gel) for retention of drug at the target site.

\section{ACKNOWLEDGEMENT}

The authors thank P.E Society's Modern College of Pharmacy, Nigdi, Pune for providing the facilities required for carrying out research work. They also thank UGC for providing funding and fellowship.

\section{CONFLICT OF INTEREST}

The authors declare no conflict of interest.

\section{ABBREVIATIONS}

HET-CAM: Hen's egg test- Chorioallantoin membrane; $\mathbf{M g S O}, \mathbf{7 H}_{2} \mathbf{O}$ : Magnesium sulphate heptahydrate; FTIR: Fourier Transform Infra Red; KBr: Potassium bromide; DG: Polyacrylic acid with divinyl glycol as crosslinking agent; DB: polyacrylic acid with divinyl benzene as crosslinking agent; HD: Polyacrylic acid with 2,5-dimethyl 1,5- hexadiene as crosslinking agent; $\mathbf{N a O H}$ : Sodium hydroxide; $\mathbf{N a H C O}_{3}$ : Sodium bicarbonate; $\mathbf{K} 2 \mathbf{H P O}_{3}$ : Potassium phosphite; NIH: National Institute of Health; FHSA: Federal Hazardous Substance Act; XRD: X ray diffraction; PII: Primary Irritation Index. 


\section{REFERENCES}

1. Rathore KS, Nema RK. An insight into ophthalmic drug delivery system. Int J Pharm Sci Drug Res. 2009;1(1):1-5.

2. Shell JW, Baker R. Diffusional systems for controlled release of drugs to the eye. Ann Ophthalmol. 1974;6(10):1037-45.

3. Bourlais CL, Acar, L, Zia H, Sado PA, Needham T, Leverge R. Ophthalmic drug delivery systems—recent advances. Pro Retin Eye Res. 1998;17(1):35-58.

4. Kaur IP, Kanwar M. Ocular preparations: the formulation approach. Drug Dev Ind Pharm. 2002;28(5):473-93.

5. Almeida $\mathrm{H}$, et al. Applications of poloxamers in ophthalmic pharmaceutical formulations: on overview. Expert Opin Drug Deliv. 2013;10(9):1223-37.

6. Sasaki $\mathrm{H}$, et al. Delivery of drugs to the eye by topical application. Prog Ret Eye Res. 1996;15(2):583-620.

7. Nirmal HB, et al. In-situ gel: new trends in controlled and sustained drug delivery systems. Int J Pharm Tech Res. 2010;2:1398-408.

8. Agarwal $\mathrm{KI}$, et al. In-situ gel formation for ocular drug delivery systems: an overview. Asia J Bio Pharm. 2010;1(4):1-7.

9. Champalal KD, Sushilkumar P. Current status of ophthalmic in-situ forming hydrogel. Int J Pharm Bio Sci. 2012;3(3):372-88.

10. Shell JW. Ophthalmic drug delivery systems. Surv Ophthalmol. 1984;29(2):117-28.

11. Burstein NL, Anderson JA. Review: corneal penetration and ocular availability of drugs. J Ocul Pharmacol. 1985;1(3):309-26.

12. Modi KA, Shelat PK. Applications of novel vesicular drug delivery system as ocular drug vehicles: a review. Int J Pharm Sci Res. 2012;3(12):4554-61.

13. Sirbat D, Heussler LM, Hoffman M, Maincent P. Ways to improve ocular bioavailability for topical applications. J Fr Opthalmol. 2000;23(5):505-9.

14. Kaur IP, Smitha R. Penetration enhancers and ocular bioadhesives: two new avenues for ophthalmic drug delivery. Drug Dev Ind Pharm. 2002;28(4):353-69.

15. Longer M, Ch'ng HS, Robinson JR. Bioadhesive polymers as platforms for oral-controlled drug delivery III: Oral delivery of chlorothiazide using a bioadhesive polymer. J Pharm Sci. 1985;74(4):406-11.

16. Park K, Robinson JR. Bioadhesive polymers as platforms for oral-controlled drug delivery: method to study bioadhesion. Int J Pharm. 1984;19(2):107-27.

17. Hui HW, Robinson JR. Ocular delivery of progesterone using a bioadhesive polymer. Int J Pharm.1985;26(3):203-13.

18. Engch H, Park H, Kelly P, Robinson JR. Bioadhesive Polymers as Platforms for Oral Controlled Drug Delivery II: Synthesis and Evaluation of Some Swelling Water-Insoluble Bioadhesive Polymers. J Pharm Sci. 1985;74(4):399-405.
19. Landgel SS, Oswal RJ, Sayarel AS, Antre RV, Patil SY. Synthesis and evaluation of some novel thiomers as mucoadhesive polymer. Der Pharma Chemica. 2012;4(4):1385-96.

20. Abdelkader H, Ismail S, Husseinc A, Wua Z, Al-Kassas R, Alanya RG. Conjunctival and corneal tolerability assessment of ocular naltrexone niosomes and their ingredients on the hen's egg chorioallantoic membrane and excised bovine cornea models. Int J Pharm. 2012;432(1-2):1-10.

21. Alany RG, Rades T, Nicoll J, Tucker IG, Davies NM. W/O microemulsions for ocular delivery: evaluation of ocular irritation and precorneal retention. J Control Release. 2006;111(1-2):145-52.

22. Abdelkader $\mathrm{H}$, Ismail $\mathrm{S}$, Kamal H, Alany RG. Design and evaluation of controlled release niosomes and discomes for naltrexone hydrochloride ocular delivery. J Pharm Sci. 2011;100(5):1833-46.

23. Luepke NP. Hen's egg chorioallantoic membrane test for irritation potential. Food Chem Toxicol. 1985;23(2):287-91.

24. Draize $\mathrm{JH}$, Woodward G, Calvery HO. Methods for study of irritation and toxicity of substances applied topically to the skin and mucus membranes. J Pharmacol Exp Therap. 1944;82(3):377-90.

25. Abraham MH, Kumarsingh R, Cometto-Muniz JE, Cain WS. Draize eye scores and eye irritation thresholds in man combined into one quantitative structure activity relationship. Toxicology in vitro. 1998;12(4):403-8.

26. Earl LK, Dickens AD, Rowson MJ. A critical analysis of the rabbit eye irritation test variability and its impact on the validation of alternative methods. Toxicology in vitro. 1997;11(3):195-204.

27. Flory PJ. Principles in Polymer Chemsitry; Ihaca, New York, Cornell University Press. 1981;336.

28. Karsa DA, Stephenson RA. Chemical aspects of drug delivery system. London Royal Society of Chemistry. 1996;235-40.

29. Buchanan KJ, Hird B, Letcher V. Crosslinked Poly (Sodium Acrylate) Hydrogels. Polymer Bulletin. 1986;15(4):325-32.

30. Pavia DL, Lapman GM, Kriz GS. Infrared spectroscopy, John Vondeling, Inroduction to spectroscopy, Brownstown, MI, U.S.A. Thomson learning Inc. 2001;29-78.

31. Park H, Robinson JR. Mechanisms of Mucoadhesion of Poly (acrylic Acid) Hydrogels. Pharm Res. 1987;4(6):457-64.

32. Pendekal MS, Tegginamat PK. Development and characterization of chitosan-polycarbophil interpolyelectrolyte complex-based 5-fluorouracil formulations for buccal, vaginal and rectal application. DARU. 2012;20(1):67.

33. Auerbach R, Kubai L, Knighton D, Folkman J. A simple procedure for the long-term cultivation of chicken embryos. Dev Biol. 1974;41(2):391-4.

\section{SUMMARY}

- Poor bioavailability of ocular drug $(\leq 1 \%$ of drug absorbed ocularly) can be attributed to precorneal factors, limited residence time, nasolachrymal drainage, relative permeability through cornea, etc. Thus prescribed dose is higher along with increased frequency. Thus there is need to minimize the dose and dosing frequency which will lead to lesser side effects.

- The aim of the present study was to synthesize and evaluate bioadhesive polymer which will not only remain adhered to conjunctiva for a long a period of time but also increase the bioavailability of drug thus reducing its side effects.

- The bioadhesive polymer synthesized was evaluated for density, polymer hydration, effect of $\mathrm{pH}$, ion and time on polymer hydration, DSC, FTIR, XRD, mucoadhesive strength ex vivo and in vivo irritation test.

- The polymer demonstrated $\mathrm{pH}$ dependent hydration properties thus swelling at neutral and basic $\mathrm{pH}$. There was no significant effect of crosslinking agent either on density or on swelling properties except for mucoadhesive strength.

- It was observed that with decrease in density of crosslinking agent, there was increase in bioadhesive strength.

- The HET-CAM results coincided with in vivo draize skin irritation and eye irritation test indicating that the polymer were found to be nonirritant to slight irritant in nature.

- DG polymer was found to most appropriate polymer for ocular delivery with optimum biaodhesive strength and least irritation potential of all the polymers synthesized. 
PICTORIAL ABSTRACT
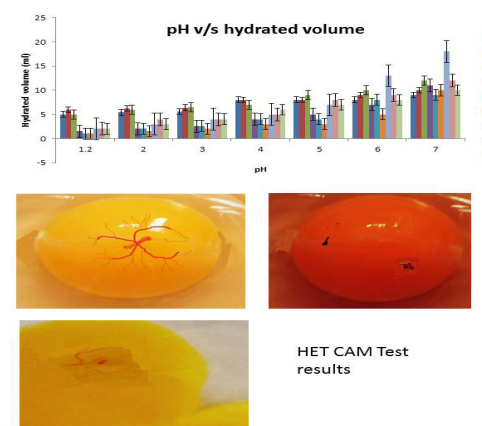

HET CAM Test

results

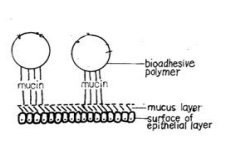

pH dependent swelling
of polymers observed

Increased bioadhesion in density of decrease in density of

Polymers were no irritant to slight irritan

\section{ABOUT AUTHORS}

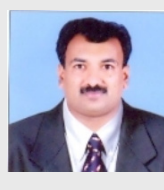

Dr. Praven Chaudhari, currently works as Principal and Professor in Pharmaceutics, P. E Society's, Modern college of Pharmacy, Pun-411044. He is President (Central) of APTI (Association of Pharmaceutical Teachers of India). He was Ex Dean at Faculty of Pharmaceutical Sciences, Savitribai Phule Pun University, Pune. He has completed his $M$. Pharm from NDMVP College of Pharmacy, Nashik and PhD from Bundelkhand University, Jhansi. He has 19 years of experience in teaching profession.

(क)

Ms. Ujwala Desai has completed her M.Pharm from P. E Society's, Modern college of Pharmacy, Pune-411044. She is currently working as PhD research scholar at P. E Society's, Modern college of Pharmacy Pune - 411044 under the guidance of Dr. Praveen Digambar Chaudhari.

Cite this article: Praveen C, Ujwala D. Synthesis and Evaluation of Water Insoluble but Swellable Bioadhesive Polymer for Ocular Drug Delivery. Indian J of Pharmaceutical Education and Research. 2019;53(2):225-35. 